\title{
Uma experiência de orientação profissional no contexto de políticas públicas
}

\author{
Camila Pereira Lisboa ${ }^{1}$ \\ Universidade Federal de Minas Gerais, Belo Horizonte-MG, Brasil
}

\section{Resumo}

Através do relato da experiência ocorrida na Diretoria de Inclusão Produtiva (em Nova Lima, MG), pretende-se mostrar como a Orientação Profissional pode ser uma estratégia eficaz para potencializar os objetivos das políticas públicas, em especial aquelas que visam a inclusão social via geração de emprego, trabalho e renda. Observou-se que os grupos de Orientação Profissional ofertados a jovens e adultos na Diretoria apresentam uma boa avaliação geral por parte de seus participantes. Os maiores desafios desses grupos são: o não comparecimento aos encontros, a dificuldade de atingir o público-alvo sugerido pelas políticas de assistência e a escassez de profissionais para ofertar as oficinas. Verifica-se, ainda, a necessidade de adaptação conceitual e metodológica para melhor contemplar as especificidades das pessoas atendidas.

Palavras-chave: orientação vocacional, inclusão social, políticas públicas

\section{Abstract: An experience of professional guidance in the context of public policies}

Through the account of the experience lived in the Directory of Productive Inclusion (in Nova Lima, Minas Gerais, Brazil), it is intended to show how professional guidance can be an effective strategy to improve the objectives of public policies, especially those aimed at social inclusion through the generation of employment, job and income. It was observed that the professional guidance groups that are offered to young people and adults in the Directory have a good overall evaluation by their participants. The main challenges of these groups are the following: absences from meetings, the difficulty of reaching the target audience suggested by the assistance policies and the shortage of professionals to be offered to the workshops. There is also a need for a conceptual and methodological adaptation to better consider the specific characteristics of the attended people.

Keywords: vocational guidance, social inclusion, public policies

\section{Resumen: Una experiencia de orientación profesional en el marco de las políticas públicas}

Através del relato de la experiencia vivenciada en el Directorio de Inclusión Productiva (en Nova Lima, Minas Gerais, Brasil), se pretende mostrar cómo la orientación profesional puede ser una estrategia eficaz para potenciar los objetivos de las políticas públicas, en especial las dirigidas a la inclusión social a través de la generación de empleo, trabajo e ingresos. Se constató que los talleres grupales de orientación profesional que se ofrecen a los jóvenes y adultos en el Directorio, reciben una buena evaluación general por parte de sus participantes. Los principales retos de estos grupos son los siguientes: las ausencias a las reuniones, la dificultad de llegar al público objetivo sugerido por las políticas de asistencia y la escasez de profesionales para realizarlos talleres grupales. También existe la necesidad de una adaptación conceptual y metodológica para abordar mejor las especificidades de las personas atendidas.

Palabras clave: orientación vocacional, inclusión social, políticas públicas

\footnotetext{
${ }^{1}$ Endereço para correspondência: Rua Chalmers, 91, Centro, 34000-000, Nova Lima-MG. E-mail: milalisb@gmail.com
} 


\section{Apresentando o contexto}

A proposta das páginas que seguem é relatar a experiência dos grupos e atendimentos individuais de Orientação Profissional realizados pela equipe da Diretoria de Inclusão Produtiva (DIP), órgão da Secretaria de Desenvolvimento Social do município de Nova Lima $(\mathrm{MG})^{2}$. Parte-se do pressuposto de que a Orientação Profissional deve se adaptar ao contexto e ao público a que é destinada. Assim sendo, quanto maior a divulgação dos diferentes espaços em que ela ocorre, maiores as possibilidades de aprimorar essa prática. Pretende-se então ofertar uma contribuição sobre essa atividade realizada no contexto das políticas públicas que envolvem a geração de emprego, trabalho e renda para as pessoas atendidas pela Assistência Social. Embora a Orientação Profissional não seja uma recomendação direta desse tipo de política, acredita-se que ela tem muito a contribuir para o acesso ao mercado de trabalho, favorecendo um desenvolvimento socioeconômico efetivo dos usuários da Assistência e dos órgãos públicos em geral que trabalhem com esse objetivo.

\section{Incentivo à empregabilidade na assistência social}

Para melhor compreender o trabalho de Orientação Profissional executado na DIP, é importante citar as políticas que orientam o funcionamento desta Diretoria. Dedicaremos esta sessão a comentar algumas delas.

As políticas de geração de emprego, trabalho e renda no país seguem a orientação mais ampla da Constituição Federal de 1988, que defende como um de seus fundamentos "os valores sociais do trabalho e da livre iniciativa" (Art. 1, inc. IV). O trabalho aparece como um direito social que deve ser assegurado a todos os cidadãos brasileiros, uma das prioridades do Governo Federal na elaboração de suas propostas.

A Lei Orgânica da Assistência Social, sancionada em dezembro de 1993, estabelece a "promoção da integração ao mercado de trabalho" como um dos objetivos da assistência social (Lei 8.742, Art. 2, inc. III). O acesso às oportunidades que compõem o mundo trabalho aparece como uma das estratégias mais eficazes de enfrentamento à pobreza, que apresenta características relativas, multidimensionais e dinâmicas ${ }^{3}$. Para além de outras formas de assistência prestadas pelo Estado a um público em condições socioeconômicas vulneráveis, o trabalho emerge como alternativa duradoura para o desenvolvimento do indivíduo atendido e de seus familiares.

Em 2011, surge o Programa Nacional de Acesso ao Ensino Técnico e Emprego (Pronatec), "com a finalidade de ampliar a oferta de educação profissional e tecnológica, por meio de programas, projetos e ações de assistência técnica e financeira" (Lei 12.513/11). Integrado ao Plano Brasil Sem Miséria, um de seus intuitos é a expansão da oferta de cursos técnicos e de qualificação profissional gratuitos $^{4}$, visando o ingresso no mercado de trabalho de seus alunos. Não por acaso o público-alvo prioritário do Pronatec são os beneficiários dos Programas Federais de Transferência de Renda, asseguradas também vagas para indígenas, quilombolas, jovens em cumprimento de medidas socioeducativas e pessoas inscritas no Cadastro Único 5 .

O Plano Brasil Sem Miséria visa não apenas a qualificação profissional, mas também a articulação com um conjunto de outras políticas que incentivem a geração de renda no país, com prioridade aos usuários da Assistência Social (MDS, 2014). Dentre essas políticas, estão a intermediação de mão de obra (em parceira com as agências do Sistema Nacional de Emprego - Sine), o estímulo ao microempreendedorismo individual e à economia solidária (através da parceria com as unidades do Sebrae espalhadas pelo país) e a oferta do microcrédito produtivo orientado (fornecido por bancos públicos brasileiros).

Diante do surgimento dessas políticas e da necessidade de assegurar o atendimento ao público prioritário mencionado, o Conselho Nacional de Assistência Social, através da Resolução 18, de 24 de maio de 2012, instituiu o Programa Nacional de Acesso ao Mundo do Trabalho (Acessuas Trabalho). Com isso, surgiu um importante marco dentro da Assistência Social: a criação de um

\footnotetext{
${ }^{2}$ A primeira versão deste artigo foi redigida em janeiro de 2016. A realidade descrita refere-se, portanto, a esse período.

${ }^{3}$ Mais informações sobre como essas características da pobreza aparecem na realidade brasileira, comparativamente a outros países, podem ser obtidas na pesquisa de Feres e Villatoro (2013). Estudos como esse indicam as dificuldades de enfrentar a pobreza através de uma única vertente, a exemplo das políticas de transferência de renda.

${ }^{4}$ Os cursos técnicos do Pronatec possuem carga horária mínima de 800 horas, enquanto os cursos de qualificação profissional - também denominados de cursos de Formação Inicial e Continuada (FIC) - são mais breves, com carga horária mínima de 160 horas.

${ }^{5} \mathrm{O}$ CadÚnico é um instrumento do Governo Federal para cadastramento de famílias de baixa renda (renda igual ou inferior a meio salário mínimo per capita ou até três salários mínimos de renda familiar mensal). O objetivo é obter um diagnóstico socioeconômico das famílias cadastradas, assegurando ainda benefícios eventuais para aquelas em situação de vulnerabilidade social, mesmo que não estejam dentro dos critérios para receber o Bolsa Família (Ex: Isenção de taxas para inscrição em concursos públicos, descontos em contas de água e luz, cadastramento no Programa Minha Casa Minha Vida, dentre outros).
} 
conjunto de medidas específicas, com financiamento próprio, voltadas para cumprir as metas de qualificação profissional e inclusão produtiva das pessoas atendidas pela Assistência Social. Assim nasceu a Diretoria de Inclusão Produtiva no município de Nova Lima. Antes dessas políticas, já eram ofertados cursos profissionalizantes, orientação profissional, orientação ao empreendedorismo e intermediação de mão de obra na Secretaria de Assistência Social. Um dos núcleos responsáveis pela execução dessas atividades era o setor de qualificação profissional do Programa Vida Nova.

Esse programa municipal foi criado em 2005, a fim de fornecer uma transferência condicionada de renda em complementação ao Bolsa Família, realizando ainda acompanhamento a famílias em situação de pobreza e extrema pobreza que residam há mais de cinco anos na cidade, visando o desenvolvimento das mesmas. A criação de um setor que trabalhasse juntamente às políticas de transferência de renda para potencializar o acesso de seus beneficiários ao mundo do trabalho seguia a ideia de auxiliar a família financeiramente numa condição emergencial, mas também ofertar condições para que ela pudesse adquirir o autossustento e então não dependesse mais da transferência de renda.

Em 2012, o setor de qualificação profissional foi transformado na Diretoria de Inclusão Produtiva, com autonomia em relação ao Programa Vida Nova e com recurso próprio proveniente do Acessuas. Além de ser responsável pela execução do Acessuas em Nova Lima, a DIP também assumiu a gestão do Pronatec no município, atuando, portanto, na interface das legislações que seguem essas duas políticas.

\section{Por que a orientação profissional nas ações da Diretoria?}

A Orientação Profissional começou a ser oferecida no setor de qualificação logo depois da criação deste. Já nas primeiras inscrições em cursos, verificou-se uma grande demanda para que ela fosse realizada. Havia aqueles que ficavam confusos na hora de escolher uma formação, muitas vezes optando pela inscrição em diferentes cursos, de áreas bem distintas, não raramente sob o discurso do "qualquer um tá bom". Muitos estavam verdadeiramente ávidos pela formação, mas tinham dificuldade de escolher diante das diversas opções que lhes eram apresentadas.

Em paralelo, o setor também encontrou alguns entraves na intermediação de mão de obra. Eram pessoas com dificuldades de (re)colocação no mercado de trabalho, de serem aprovadas em processos seletivos ou se manterem na empresa. Aqui, também se repetia o dilema da escolha, onde a urgência pelo trabalho impedia alguns candidatos de fazerem uma avaliação mais criteriosa sobre qual oportunidade escolher em muitas situações.

Como resultado desse quadro, foram constatadas sucessivas evasões dos cursos de qualificação profissional. Uma pesquisa à época apontou que um dos grandes motivos para isso era o fato do curso não estar de acordo com os interesses dos candidatos. Os professores, instituições ofertantes e métodos eram avaliados positivamente, mas os temas abordados não eram coerentes com o que o aluno desejava exercer em seu futuro profissional.

$\mathrm{Na}$ intermediação, algumas empresas parceiras reclamavam do desempenho dos candidatos encaminhados aos processos seletivos. Muitos ou eram reprovados ou eram dispensados logo no período de experiência, por causa de comportamentos julgados inadequados pela empresa, e que os candidatos achavam naturais (a exemplo de chegar atrasado, com vestimentas incompatíveis para a vaga, não saber falar sobre suas qualidades ou expectativas profissionais etc.).

Para amenizar esses problemas que estavam comprometendo a eficácia das ações do setor, a equipe de Psicologia contratada à época concluiu que a Orientação Profissional poderia ser uma estratégia útil. A partir de então, as inscrições em cursos passaram a ser acompanhadas pelos atendentes, que eram psicólogos, mas também: profissionais administrativos, pedagogos, assistentes sociais ou outros treinados pela equipe da Psicologia. Esses atendentes estavam prontos para esclarecer dúvidas sobre o que eram os cursos e o que faziam os profissionais daquela área, incitando também reflexões sobre o que a pessoa pretendia com a formação e quais eram suas expectativas de atuação no mercado de trabalho. O intuito era auxiliar essa pessoa a escolher uma formação mais compatível com suas habilidades e com suas expectativas para o futuro de longo prazo.

Para os casos em que a dúvida prevalecia, ou naqueles que apresentavam alguma outra peculiaridade que necessitava de um atendimento mais delongado e específico, passou a ser feito o encaminhamento para a equipe de Psicologia, que iniciava o processo de Orientação Profissional propriamente dito. Em geral, os atendimentos ocorriam no período de 1 a 5 sessões, a depender do caso atendido.

$\mathrm{Na}$ intermediação de mão de obra, a equipe começou a acompanhar cada processo seletivo, desde o encaminhamento, passando pela seleção (que ocorria na própria empresa ou no espaço físico do setor de qualificação), até o resultado relatado pelas empresas e pelos candidatos. O objetivo era ter uma visão prática - para além do que a teoria sobre recrutamento e seleção de pessoas já nos apontava - a respeito do que as empresas avaliavam a partir de suas culturas, áreas de atuação e cargos para os quais contratavam. Da maior compreensão sobre os diferentes 
perfis buscados nas diferentes vagas, começamos a formular um programa de orientação específico a processos seletivos, que ocorria também através de atendimentos individuais ou em grupo.

Os grupos de Orientação profissional surgiram no intuito de atender a um número maior de pessoas, com o desafio de manter o foco nas dificuldades, dúvidas e potencialidades de cada sujeito atendido. Embora a equipe desejasse estender os atendimentos individuais a todo o público, não havia um número suficiente de profissionais para tal demanda. Assim, apenas os casos avaliados como mais críticos ou urgentes (aqueles que não poderiam aguardar as datas de ocorrência do grupo), eram encaminhados para o atendimento individual.

Foram criados diferentes grupos, de acordo com o objetivo daqueles que buscavam o setor. Assim, surgiram os grupos de orientação para as primeiras escolhas profissionais e para o primeiro emprego, em geral voltados para adolescentes ${ }^{6}$. Havia também os grupos preparatórios para processos seletivos, os grupos de orientação para atividades de empreendedorismo e economia solidária, além daqueles destinados aos recém-admitidos em empresas e aos alunos dos cursos de qualificação que promovíamos.

Cada grupo tinha uma duração média de 2 semanas e era executado por psicólogos e estagiários de Psicologia, formando uma equipe de cerca de 22 pessoas. Com o passar dos anos, a política de estágio deixou de ser ofertada no município, o que comprometeu as ações do setor. Embora os atendimentos individuais permaneçam ${ }^{7}$, apenas alguns desses grupos puderam continuar ocorrendo, e com uma periodicidade menor (um dia ou, no máximo, uma semana).

Além dos desafios institucionais, percebemos alguns outros no âmbito do público atendido. Enquanto estudávamos textos e técnicas voltadas, em geral, para a Orientação executada com jovens de escolas privadas com o dilema de escolher um curso universitário, nosso público nos colocava desafios bem mais amplos: alguns jovens envolvidos com o uso de drogas e/ou com o tráfico de drogas, algumas jovens grávidas ou já com filhos, jovens encerrando o ensino médio que não sabiam o que era vestibular ou que não acreditavam ter condições de cursar uma Faculdade. No grupo de adultos, os desafios não eram menores: situações de violência familiar, submissão a condições precárias de trabalho diante da urgência imposta pela pobreza, escolaridade baixa diante das expectativas descritas, dentre outros.

Com esses exemplos, não desejamos recair em estigmas e caricaturas que descrevem o público atendido pela Assistência Social, sendo ele muito diverso e, em muitos casos, fugindo totalmente aos exemplos apresentados. Nossa intenção é apenas exemplificar as nossas dificuldades iniciais em adaptar nossas técnicas - seja nos grupos ou atendimentos individuais - ao que o contexto apresentava. Em todo o caso, havia um público diversificado, que exigia métodos adaptados a suas necessidades. Vivenciamos a dificuldade de encontrar referências teóricas ou outras experiências executadas pelos serviços públicos que nos auxiliassem.

Descreveremos brevemente algumas considerações teóricas que auxiliaram a ampliar o nosso olhar, a fim de que pudéssemos criar ferramentas mais adaptadas ao trabalho na DIP. Em seguida, partiremos para a descrição da experiência atual da equipe, seguida de alguns desafios colocados por esta prática.

\section{A orientação profissional e seu público}

Dada a diversidade de definições na literatura sobre o que é a Orientação Profissional, trazemos aqui uma descrição de Rodolfo Bohoslavsky, por acreditarmos que ela sintetiza bem o trabalho exercido na DIP: "uma ampla gama de tarefas, que inclui o pedagógico e o psicológico, em nível de diagnóstico, de investigação, de prevenção", uma autêntica "psicoprofilaxia individual e social" (Bohoslavsky, 1998, p. 137) ${ }^{8}$. Com isso, percebemos que

\footnotetext{
${ }^{6}$ Todas as ações deste setor e, posteriormente, da Diretoria de Inclusão Produtiva, são voltadas para jovens de 14 anos, seguindo as orientações legais da permissão para o trabalho apenas a partir dessa idade. Para mais informações, ver os Arts. 60 a 69 do ECA; os Arts. 402 a 401 da CLT; a Emenda Constitucional no 20; o Decreto $n^{\circ} 5.598$, de $1^{\circ}$ de dezembro de 2005; e Portaria $n^{\circ} 20$, de 13 de setembro de 2001, do Ministério do Trabalho e Emprego.

${ }^{7}$ A equipe de Psicologia decidiu manter o número de atendimentos individuais, mesmo diante da redução do número de oficinas, devido à complexidade dos casos recebidos. A demanda pela escuta, avaliação e encaminhamento psicológico se manteve, então ela teve que ser priorizada em relação às oficinas. Além disso, os atendimentos individuais eram realizados exclusivamente pelos psicólogos, ao passo que alguns grupos eram facilitados ou co-facilitados por estagiários de Psicologia. Assim, com a saída dos estagiários, os grupos de orientação profissional que já ocorriam foram os mais prejudicados.

${ }^{8}$ Bohoslavsky (1998) se refere aqui mais especificamente à Orientação Vocacional. No decorrer do texto, preferimos adotar o termo mais genérico "Orientação Profissional", para se referir tanto às orientações voltadas à escolha de uma formação quanto àquelas que se destinam a aspectos mais amplos da vida profissional (colocação e recolocação no mercado de trabalho, orientação a atividades empreendedoras e à mudança de carreira, dentre outros dramas que envolvam a relação do sujeito com o mundo do trabalho).
} 
atuar em Orientação Profissional exige uma atenção ao sujeito enquanto ser integral - na relação de sua subjetividade com o universo social.

De fato, a objetividade e a subjetividade do homem estão presentes no mundo do trabalho, "afeto e razão em cada gesto produtivo" (Codo, 2003, p. 179). O trabalho localiza-se no mundo social enquanto um dos critérios de inclusão dos sujeitos na sociedade. Aqueles excluídos do mundo produtivo costumam ser culpabilizados por sua ineficácia ${ }^{9}$, embora outros fatores também operem nesse processo: as realidades macro e microeconômicas, as redes de apoio social, as políticas de incentivo à educação e à profissionalização de qualidade, dentre muitos outros. Seja como for, ainda segundo Codo (2003), uma adequada orientação que considere a integração dessas duas esferas - a subjetiva e a social - é importante tanto na remediação quanto na prevenção do adoecimento mental. Socialmente, os ganhos também são numerosos: menor número de turnover e absenteísmo nas empresas, profissionais mais motivados à oferta de serviços de qualidade à população e ao desenvolvimento de novas tecnologias produtivas que podem representar avanços sociais significativos.

A Orientação Profissional pode então ser considerada como promotora de saúde, ao ampliar a consciência do indivíduo sobre a realidade que o cerca e instrumentá-lo para agir, ressignificar relações, transformar essa realidade, e resolver as dificuldades que ela lhe apresenta (Bock, 2011). Para tanto, é necessário que sejam considerados aspectos do desenvolvimento psicossocial desse sujeito, situacionais, de sua educação formal, de suas experiências profissionais, de sua história, expectativas, possibilidades, acervo de competências e capacidade de planejamento (Zacharias, 2010).

Patterson e Eisenberg (2013) fazem uma interessante descrição do que seria o objetivo do processo de orientação ${ }^{10}$ : capacitar o sujeito "a dominar diferentes situações da vida, a engajar-se em atividades que produza crescimento e a tomar decisões" (p. 01). Essa é uma das premissas que adotamos: a de que o processo de orientação profissional deve estimular a pessoa atendida a refletir sobre suas características, suas possibilidades, expectativas, condições factuais do mercado de trabalho, dentre outros elementos que a auxiliem a fazer escolhas conscientes sobre a sua vida profissional.
O "orientador" profissional, nesse sentido, exerce muito mais a função de um facilitador do processo de escolha, que é invariavelmente realizado pelo próprio "orientando". Em alguns casos, a atitude mais útil do técnico é apresentar um conjunto de alternativas construtivas, de acordo com os elementos de análise que lhes são oferecidos pelo orientando - aquele quem deve fazer a escolha ao final (May, 2009).

Tal processo convoca a grande responsabilidade desse orientador. A ele, cabe o papel de incentivar a reflexão dos sujeitos sobre a relação de sua identidade individual com o trabalho que é executado, o significado de seu trabalho e o que este produz - para si e para outras pessoas (Lehman, 2010). Toda prática de Orientação Profissional deve ser feita de modo realista, considerando os diferentes contextos onde ele ocorre. Tratando de um público em vulnerabilidade socioeconômica, Valore (2010) ressalta que

caberá ao orientador saber lidar com as possiveis diferenças quanto à realidade social de seus orientandos, sem escamoteá-las em nome de um discurso falsamente democrático em que se mistifica a 'igualdade de oportunidades' em uma sociedade marcada, o tempo todo, pela exclusão. Em contrapartida, caberá ao orientador, igualmente, conseguir se deparar com seus próprios pré-conceitos e com representações construídas a respeito de tais diferenças que, em geral, configuram tal comunidade como carente, desfavorecida, desprivilegiada. (Valore, 2010, pp. 77-78)

Não é papel do orientador apontar caminhos ou fazer escolhas pelos candidatos, a partir de seus próprios referenciais de mundo. Aqui, é necessário escutar e compreender as demandas específicas de cada orientando, com o cuidado de não recair em rótulos, mas realizando uma análise realista sobre quais as condições concretas do sujeito em atingir seus objetivos. O intuito não é desencorajar aquele que idealiza seu futuro, mas ajudá-lo na percepção de suas reais condições de alcançar tais metas. Evita-se frustração, ao mesmo tempo em que se incentiva a elaboração de um planejamento que enumere os passos a serem dados para que os referidos objetivos sejam concretizados, sendo esse o desejo do orientando.

\footnotetext{
${ }^{9}$ Uma interessante análise da culpabilização perversa atribuída socialmente aos indivíduos, sendo ela mesma produtora de mais exclusão, pode ser encontrada na obra de Sawaia (2014).

${ }^{10}$ Os autores se referem ao processo de Aconselhamento e Orientação em Psicologia, que abrange, dentre outras práticas, a Orientação Profissional.
} 
Em todo caso, é necessário que as técnicas sejam adaptadas ao público, "oferecendo aos participantes oportunidades de reflexão e mudanças de atitude sobre o sentido do trabalho nas suas múltiplas dimensões, sociais, políticas e pessoais" (Ferreti, 1988, p. 47). Para além da mera informação profissional, é importante fomentar a crítica no orientando, que deve refletir sobre sua própria identidade, bem como sobre o contexto social, econômico e político com o qual ela se relaciona.

No que tange à prática da Orientação Profissional no contexto público, ela está mais relacionada na literatura ao trabalho realizado com estudantes de escolas públicas ou a atividades clínicas exercidas em algumas comunidades isoladamente, em geral associadas à oferta de serviços gratuitos pertencentes a cursos de Psicologia na exigência de seus estágios profissionalizantes (Abade, 2005; MeloSilva, Lassance, \& Soares, 2004). Ela ainda não se encontra inserida efetivamente nas políticas públicas nacionais, embora tenham muito a oferecer em diferentes espaços.

Através do presente relato, foi citada aqui uma possibilidade na interface entre políticas dos Ministérios da Educação, do Desenvolvimento Social e do Trabalho e Emprego ${ }^{11}$. No caso da DIP, a Orientação Profissional surgiu a partir da necessidade de maior eficácia de nossas ações, assegurando um melhor acesso, quantitativo e qualitativo, do público atendido ao mercado de trabalho. Certamente, existem muitas outras possibilidades, na exigência de assegurar políticas de incentivo à autonomia, participação, desenvolvimento pessoal e comunitário, bem como ações interdisciplinares entre diferentes agentes e políticas públicas (Machado, 2009).

É preciso que as práticas administrativas sejam planejadas e executadas de acordo com as especificidades das demandas populares, caracterizando a dimensão sociopolítica na gestão pública (Paes, 2005). Eis uma responsabilidade do Estado, enquanto propositor de políticas públicas, mas também da população e dos técnicos responsáveis pela execução dessas políticas. Em conjunto, essas esferas são capazes de propor métodos mais adaptados à realidade social à qual se deseja alcançar.

A Assistência Social é um exemplo. Nela, sucessivas políticas de inclusão produtiva fracassaram, até que foram formuladas estratégias que contemplassem as especificidades desse grupo. Muito desse público não aderia a propostas de qualificação profissional devido à divulgação inadequada dos cursos, à alta escolaridade que estes exigiam, à falta de dinheiro para custear o deslocamento até a escola ou aos horários em que os cursos eram ofertados. O envolvimento dos técnicos da Assistência na mobilização das pessoas, a oferta de uma ajuda de custo por parte do Governo Federal, a execução de cursos noturnos e para diferentes graus de escolaridade foram algumas medidas que fizeram com que esse tipo de política começasse a atingir seus objetivos. Ao invés de ações pontuais, fragmentais e meramente assistencialistas, iniciou-se uma efetiva inclusão produtiva, ao se considerar as peculiaridades do público a que tais ações se destinavam (Cassiolato \& Garcia, 2014; Costa \& Muller, 2014; Souza, 2013).

Passaremos agora ao relato propriamente dito da experiência atual na Diretoria de Inclusão Produtiva. Com isso, será possível perceber que a Orientação Profissional vai se moldando, a partir das necessidades da Diretoria e do público que ela atende. Veremos o trabalho executado em suas potencialidades e muitos desafios, estando ainda em contínuo aperfeiçoamento.

\section{A experiência da Orientação Profissional na DIP}

Atualmente, a Diretoria de Inclusão Produtiva conta com uma equipe de 15 membros para a execução de suas ações. São cinco psicólogos, dois Assistentes Sociais, dois Pedagogos, um Administrador, um profissional de Marketing e mais quatro profissionais de ensino médio, entre concursados e profissionais comissionados. Eles se distribuem entre as atividades já mencionadas: mobilização do público-alvo; divulgação e inscrições em cursos de qualificação profissional gratuitos; intermediação de mão de obra; oferta de microcrédito produtivo orientado, em parceria com a Caixa Econômica Federal; atendimentos individuais e realização de oficinas para a orientação/apoio a iniciativas empreendedoras e de economia solidária; encaminhamentos gerais para outros serviços ofertados pela rede pública do município; e orientação profissional, foco deste texto. Embora constituam ações diferentes, elas interagem para possibilitar o objetivo da Diretoria, que é favorecer a integração do público atendido ao mundo do trabalho.

A Orientação Profissional recebe pessoas encaminhadas tanto pela própria equipe da Diretoria quanto de outros órgãos da rede pública do município. Os atendimentos individuais em Orientação Profissional são realizados exclusivamente pela equipe da Psicologia. Os grupos e oficinas são feitos geralmente em dupla, também com a participação de pelo menos um membro da Psicologia.

\footnotetext{
${ }^{11}$ Via integração entre as propostas do Pronatec, Acessuas e de outras normativas para a geração de emprego, trabalho e renda no país.
} 
Os atendimentos individuais são realizados em poucas sessões (ainda ocorrem entre um e cinco sessões, a depender o caso). Identificada a necessidade de um acompanhamento psicológico com um prazo maior, a pessoa é encaminhada para a psicoterapia, realizada nos centros de saúde pública da cidade.

As oficinas com o tema da Orientação Profissional são realizadas para grupos entre três e 20 pessoas, que se inscrevem espontaneamente e escolhem o melhor dia e horário para participarem da atividade ${ }^{12}$. Há pelo menos um grupo de Orientação Profissional ofertado mensalmente para jovens nos turnos da manhã e tarde; o mesmo ocorre no caso do público adulto. Conforme já mencionado, os temas abordados variam de acordo com o objetivo do grupo: a escolha profissional, preparação para processos seletivos, dentre outros.

As oficinas são realizadas através de técnicas vivenciais, visando uma reflexão racional, mas também buscando envolver os sujeitos de forma integral, no seu "pensar sentir e agir" (Afonso, 2010, p. 09). Busca-se acessar a vivência do sujeito, através de seus aspectos emocionais e inconscientes, para além de trabalhar com conteúdos no nível da mera informação. Concluímos que as técnicas vivenciais e em dinâmica de grupo são um poderoso instrumento para motivar a reflexão, a crítica e a participação de todos os membros do grupo em suas atividades.

Existe um planejamento prévio das técnicas e temas a serem trabalhados nas oficinas, mas também uma flexibilidade para abordar temas emergentes do próprio grupo e através de dinâmicas diferentes, a depender das necessidades que dele emergem ${ }^{13}$. Essa flexibilidade surge do necessário respeito aos conhecimentos e demandas dos próprios membros das Oficinas, um respeito a cada um deles enquanto indivíduos e a toda a sua "experiência social" (Freire, 1996, p. 30), também ela carregada de conhecimentos e experiências a compartilhar. Segundo Ramalho (2011), isso exige uma atenção às peculiaridades de cada grupo e às forças que neles atuam - forças internas (dos próprios indivíduos) e pressões externas (decorrentes da relação dos indivíduos com o ambiente social que os cercam).

Quanto aos técnicos responsáveis pelas oficinas, estes buscam assumir um papel de "facilitadores", não lhes cabendo "conduzir" uma discussão ou "transmitir" conhecimentos, mas facilitar uma aprendizagem significativa. Eles "facilitam" porque não provocam a mudança, mas incentivam a mudança a ser realizada pelo próprio sujeito a partir de suas próprias potencialidades. A respeito da aprendizagem significativa, objetivo central das oficinas da Diretoria, poderíamos sintetizá-la de acordo com a definição de Rogers (2012, p. 322):

Aquela que provoca uma modificação, quer seja no comportamento do indivíduo, na orientação da ação futura que escolhe ou nas suas atitudes e na sua personalidade. É uma aprendizagem penetrante, que não se limita a um aumento de conhecimentos, mas que penetra profundamente todas as parcelas da sua existência.

Ao adotarmos essas estratégias, temos percebido que os resultados das Oficinas de Orientação Profissional impactam de modo concreto em nossas outras ações. Desde que a Orientação Profissional começou a ser ofertada, quer através dos atendimentos individuais ou das práticas em grupo, o número de evadidos dos cursos de qualificação devido à expectativa frustrada em relação ao curso escolhido é quase nulo. Outro exemplo é o número de candidatos aprovados em processos seletivos, que cresceu substancialmente. Apesar dos resultados positivos, que têm mantido a oferta da Orientação Profissional na Diretoria há mais de 10 anos, são muitos os desafios que esse trabalho enfrenta. Relataremos alguns deles.

\section{Alguns desafios da prática}

Uma das primeiras dificuldades enfrentadas para a execução da Orientação Profissional na Diretoria de Inclusão Produtiva é o não comparecimento das pessoas inscritas. Conforme mencionado, as inscrições são espontâneas. Existem exceções, a exemplo daqueles grupos realizados em escolas ou imediatamente antes de processos seletivos que ocorrem no espaço físico da Diretoria. Em alguns desses casos, todos os alunos encaminhados pelos professores ou todos os candidatos à vaga de emprego participam da oficina, embora esclareçamos que tal participação não é obrigatória.

\footnotetext{
${ }^{12}$ As Oficinas de Orientação Profissional da Diretoria de Inclusão Produtiva eram ofertadas nos turnos da manhã, tarde e noite. Com a redução do quadro de colaboradores, ficou restrita aos horários da manhã e tarde.

${ }^{13}$ Cada grupo apresenta sua especificidade, que exige a flexibilização das técnicas em muitos casos. Um exemplo são os grupos mais retraídos, nos quais é necessário um número maior de dinâmicas que estimulem a desinibição e a comunicação dos participantes. Temas recorrentes que surgem nesse processo também merecem atenção. Alguns deles relacionam-se com a gravidez da adolescência, o uso de álcool e outras drogas, além da situação de violência familiar. Tais demandas são acolhidas e trabalhadas transversalmente aos temas inicialmente propostos, com o cuidado de não perder o foco do grupo, que é a Orientação Profissional.
} 
Em geral, os integrantes dos grupos são aqueles que nos procuram para fazer inscrição em cursos de qualificação ou para a intermediação de mão de obra; são raros os casos que buscam se inscrever apenas para as oficinas. Além da informação oral durante o atendimento sobre os objetivos das Oficinas de Orientação Profissional, cada pessoa que manifesta interesse em participar do grupo recebe um informativo sobre o que é a Orientação Profissional e seus objetivos. Nesse mesmo folheto, está o dia e o horário em que o encontro será realizado, segundo a preferência apontada pela própria pessoa. $\mathrm{Na}$ véspera de cada grupo, a equipe liga para o inscrito, lembrando-o da ocorrência da atividade no dia seguinte - uma estratégia importante para assegurar a presença dos participantes.

A nível de ilustração, consideraremos apenas a amostra entre janeiro e outubro de 2015, ano da escrita deste artigo. Foram oferecidas 47 Oficinas de Orientação Profissional, para as quais se inscreveram 624 pessoas. Destas, conseguimos contato telefônico com apenas 310 pessoas, sendo que o restante dos telefones estavam indisponíveis no momento da ligação, ou a chamada não era atendida. Ao final, compareceram 263 participantes, menos da metade dos inscritos.

A avaliação das oficinas por parte dos candidatos é bastante positiva, seja a partir de seus relatos orais ao final do encontro ou pela avaliação - escrita e anônima - que preenchem, atribuindo uma nota a aspectos como conteúdo trabalhado, didática, facilitador e local do encontro, além de poderem deixar um texto com críticas e sugestões. Em notas de 0 a 10, as avaliações escritas registraram uma média de $99 \%$ de aprovação ao conteúdo, à didática e ao facilitador da oficina. Já a aprovação atribuída ao local desta, foi de $94 \%$. Essa avaliação mais baixa do local se refere a uma das salas da Diretoria, que foi descrita por alguns participantes como possuindo uma acústica ruim. No registro qualitativo de sugestões, os participantes sugeriram, dentre outros, a adoção de vídeos como estratégia metodológica.

Apesar das boas avaliações dos participantes, o que justificaria uma boa propaganda "boca a boca" entre os beneficiários da Assistência, o número de pessoas que se inscrevem nos grupos e não comparecem é alto. Em pesquisa posterior à ocorrência do grupo, constatamos que boa parte das pessoas que não comparecem são aquelas com as quais não conseguimos contato telefônico e que justificam a ausência por não terem se lembrado do dia da oficina. Entretanto, cogitam-se algumas outras razões.
Uma delas é a associação que pensamos ser feita entre a participação na oficina e a inclusão em outros serviços. Durante os cadastros para cursos ou para a intermediação, oferecemos a Orientação Profissional como mais uma possibilidade de inserção, explicando seus possíveis benefícios. Cogitamos que muito da aceitação para participar das oficinas que é feita nesse momento ocorre porque algumas pessoas ou não querem frustrar a oferta do atendente ou condicionam a inserção nas outras ações à participação nesses encontros. Acreditamos que isso ocorra, apesar do empenho dos atendentes em explicar que são atividades diferentes e que a Orientação não é obrigatória.

Outro desafio decorre dos casos encaminhados. Para citar um exemplo, muitas pessoas são enviadas para a Diretoria por técnicos do Bolsa Família, que atuam no mesmo prédio que a equipe da DIP. Em alguns casos, percebe-se que há pessoas que optam por fazer a inscrição nas oficinas por essa ser uma recomendação de tais técnicos, com medo da perda do seu benefício. Assim, muitos se inscrevem, mas não comparecem no dia do grupo.

Existe ainda certa dificuldade para atender o público-alvo prioritário sugerido pelo Acessuas e pelo Pronatec, em especial as pessoas com deficiência. Embora sejam raras as inscrições desses sujeitos, existem inadequações na infraestrutura local e a falta de qualificação da equipe para lidar com tais pessoas, principalmente aquelas que exigem a comunicação em libras. O número reduzido de profissionais, que dividem sua atenção com outras ações, dificulta a oferta de um quantitativo maior de atendimentos individuais e da oferta de oficinas, que também poderiam ocorrer num número maior de dias caso houvesse mais facilitadores disponíveis para tal.

Outro desafio importante é a limitação de utilização do recurso financeiro. Embora sejamos guarnecidos pelo recurso vinculado do Acessuas, o uso do mesmo é restrito ${ }^{14} \mathrm{e}$ ainda depende da aprovação do município para ser utilizado. É o que impede, por exemplo, a contratação de mais colaboradores para atuarem especificamente com as atividades desta política; a legislação que regula do recurso permite isso, porém existe o entrave a lei de responsabilidade fiscal do município. Este é apenas um caso entre outros em que os entraves burocráticos na execução das políticas públicas dificultam a que elas ocorram com maior eficácia.

Há também o desafio já anunciado, de encontrar livros, textos ou outras referências que contribuam para a qualificação técnica da equipe, no que se refere à pratica da Orientação Profissional no contexto das políticas

${ }^{14}$ Especificações sobre a utilização deste recurso podem ser encontradas na Resolução 18, de 24 de maio de 2012. 
públicas. Disso decorre que o profissional que atua nesse tipo de contexto necessita buscar conhecimentos transversais para adaptá-los a suas atividades, tais como: Orientação Profissional em outros contextos, legislação pública, trabalho com pessoas e comunidades, trabalho com pessoas em situação de vulnerabilidade etc. De todo modo, sustenta-se a certeza da necessidade de manter o olhar aberto e atento para captar as necessidades das demandas do público específico com o qual se trabalha neste programa, adaptando ou criando novas técnicas que visem atingir essas pessoas de modo mais efetivo.

Recebemos um público muito diverso, de diferentes faixas etárias, níveis de escolaridade, ocupações e expectativas em relação ao mundo do trabalho. Daí surge o desafio dessa criação ou adaptação constante das nossas estratégias de mobilização e de ação. Destaca-se também a importância de pesquisas qualitativas, que a equipe procura fazer com o intuito de compreender melhor os entraves ao trabalho, com vistas ao seu aprimoramento.

Para a superação de tais desafios, é preciso que exista o apoio da administração municipal e dos órgãos executores de políticas públicas como um todo. Mesmo que esse trabalho não seja uma exigência direta das políticas do Acessuas ou do Pronatec, seus resultados têm se mostrado importantes para a eficácia delas no município. A ação conjunta com outros atores da rede municipal tem sido essencial, na medida em que os mútuos encaminhamentos apenas fortalecem as possibilidades de inclusão no mercado de trabalho ${ }^{15}$.

Essas foram apenas algumas das dificuldades enfrentadas pela Diretoria de Inclusão Produtiva. Ao invés de representarem entraves ao trabalho, elas constituem desafios à construção de estratégias novas, que potencializem as propostas contidas nas políticas públicas que orientam as nossas ações.

\section{Considerações finais}

Esse artigo não se propõe a apresentar conclusões definitivas sobre a prática da Orientação Profissional no contexto descrito. O intuito dele é provocar uma interlocução com outros atores que possam auxiliar a estender essa discussão a outros locais.

Assim, espera-se que a Orientação Profissional ganhe mais espaço na execução de políticas públicas, em especial aquelas voltadas à geração de emprego, trabalho e renda. Isso traria benefícios para os técnicos que a realizam, gerando um novo campo de atuação. Os benefícios também seriam para as próprias políticas, que adquiririam novas ferramentas para assegurar sua eficácia.

No caso da interlocução com a Assistência Social, os ganhos são ainda maiores. Esse é um lugar fértil para novas proposições que possam ser efetivas para agir em conjunto com outras políticas emergenciais como o Bolsa Família. Considerando que a concessão deste benefício para famílias em situação de pobreza não deve ser vitalícia, é necessário pensar em ferramentas que facilitem a seus beneficiários acessar o mundo do trabalho, construindo soluções mais duradouras para o combate à pobreza e à exclusão social. Nesse sentido, a Orientação Profissional certamente tem muito a contribuir.

\section{Referências}

Abade, F. L. (2005). Orientação profissional no Brasil: uma revisão histórica da produção científica. Revista Brasileira de Orientação Profissional, 6(1), 15-24. Recuperado em 27 de setembro de 2017, de http://pepsic.bvsalud.org/pdf/ $\mathrm{rbop} / \mathrm{v} 6 \mathrm{n} 1 / \mathrm{v} 6 \mathrm{n} 1 \mathrm{a} 03 . \mathrm{pdf}$

Afonso, M. L. M. (2010). Oficinas em dinâmica de grupo: um método de intervenção psicossocial (3 ${ }^{\mathrm{a}}$ ed.). São Paulo: Casa do Psicólogo.

Bock, A. M. (2011). A escolha profissional em questão (3a ed.). São Paulo: Casa do Psicólogo.

Bohoslavsky, R. (1998). Orientação vocacional: a estratégia clínica (11a ed.). São Paulo, Martins Fontes.

Cassiolato, M. M. C., \& Garcia, R. C. (2014). Pronatec: múltiplos arranjos e ações para ampliar o acesso à educação profissional. Brasília: IPEA.

\footnotetext{
${ }^{15}$ Destaca-se a parceria com a secretaria de Educação, para onde encaminhamos pessoas que necessitam dar continuidade a seus estudos. Os serviços da Secretaria de Saúde, em especial os Centros de Atendimento Psicossocial (CAPS) e as Unidades Básicas de Saúde são essenciais para que os encaminhados tenham suporte psicológico ou de saúde física, essenciais em muitas situações, para que a pessoa consiga ter uma boa avaliação em processos seletivos e manter-se no emprego. Os Centros de Referência da Assistência Social - Básica e Especializada (CRAS e CREAS), são parceiros ativos na garantia de direitos socioassistenciais. São muitos outros parceiros, sem os quais o trabalho da Diretoria não seria possível.
} 
Codo, W. (2003). Um diagnóstico integrado do trabalho em ênfase em saúde mental. In M. G. Jacques, \& W. Codo (Orgs.), Saúde mental \& trabalho: leituras (2a ed.). Petrópolis, Vozes.

Constituição Federal, de 5 de outubro de 1988 (48a ed.) (1988). Brasília: Congresso Nacional, Câmara dos Deputados.

Costa, P. V., \& Muller, L. H. (2014). A qualificação profissional na estratégia de inclusão produtiva urbana do Plano Brasil sem Miséria. Brasília: MDS.

Feres, J. C., \& Villatoro, P. (2013). A viabilidade de se erradicar a pobreza: uma análise conceitual e metodológica. Cadernos de Estudos Desenvolvimento Social em Debate, 15, pp. 1-88.

Ferreti, C. J. (1988). Uma nova proposta de orientação profissional. São Paulo: Cortez.

Freire, P. (1996). Pedagogia da autonomia: saberes necessários à prática educativa. São Paulo: Paz e Terra.

Lehman, Y. P. (2010). Orientação profissional na pós-modernidade. In R. S. Levenfus, \& D. H. P. Soares (Orgs.), Orientação vocacional ocupacional ( $2^{\mathrm{a}}$ ed.). Porto Alegre: Artmed.

Lei n. 12.513, de 26 de outubro de 2011 (2011). Brasília: Congresso Nacional, Câmara dos Deputados.

Lei n. 8.742, de 7 de dezembro de 1993 (1993). Brasília: Ministério do Desenvolvimento Social e Combate à Fome.

Machado, L. (2009). Orientação profissional: a necessária renovação conceitual e re-organização política. In F. Blas, F., \& J. Planells, Desafios atuais da educação técnico-profissional. Madri: OEI; Fundação Santillana.

May, R. 2009. A arte do aconselhamento psicológico (17a ed.). Petrópolis: Vozes.

Melo-Silva, L. L., Lassance, M. C. P., \& Soares, D. H. P. (2004). A orientação profissional no contexto da educação e trabalho. Revista Brasileira de Orientação Profissional, 5(2), 31-52. Recuperado em 27 de setembro de 2017, de http://pepsic.bvsalud.org/pdf/rbop/v5n2/v5n2a05.pdf

Ministério do Desenvolvimento Social e Combate à Fome (MDS) (2014). O Brasil sem miséria. Brasília: MDS.

Paes, A. P. (2005). Por uma nova gestão pública. Rio de Janeiro: Editora FGV.

Patterson, L. E., \& Eisenberg, S. (2013). O processo de aconselhamento (4a ed.). São Paulo: Martins Fontes.

Ramalho, C. M. R. (2011). Psicodrama e dinâmica de grupo. São Paulo: Iglu.

Resolução 18, de 24 de maio de 2012 (2012). Brasília: Conselho Nacional de Assistência Social.

Rogers, C. R. (2012). Tornar-se pessoa (6a ed.). São Paulo: Martins Fontes.

Sawaia, B. (Org.) (2014). As artimanhas da exclusão (14ª ed.). Petrópolis: vozes.

Souza, F. V. F. (2013). Assistência social e inclusão produtiva: algumas indagações. O Social em Questão, 30, pp. 287298. Recuperado em 08 de janeiro de 2016, de http://osocialemquestao.ser.puc-rio.br/media/OSQ_30_Souza_14.pdf

Valore, L. A. (2010). Orientação profissional em grupo na escola pública: direções possíveis, desafios necessários. In R. S. Levenfus, \& D. H. P. Soares (Orgs.), Orientação vocacional ocupacional ( $2^{\mathrm{a}}$ ed.). Porto Alegre: Artmed.

Zacharias, J. J. M. (2010). Breve guia para orientação de carreira e coaching. São Paulo: Vetor.

Recebido: $18 / 01 / 2016$

$1^{a}$ reformulação: 02/02/2017

$2^{a}$ reformulação: $21 / 06 / 2017$

Aceite final: 19/08/2017

Sobre a autora

Camila Pereira Lisboa é Bacharel em Psicologia, Especialista em Gestão Pública e Mestre em Psicologia Social. $\mathrm{Na}$ época da escrita do artigo, era Referência Técnica da Diretoria de Inclusão Produtiva da Prefeitura de Nova Lima (MG). 